\title{
ESTIMATING THE PREVALENCE OF OBSESSIVE COMPULSIVE DISORDER IN EUROPE OVER THE NEXT TEN YEARS
}

\section{Introduction:}

Obsessive compulsive disorder (OCD) is a debilitating disorder, which is characterized by the presence of obsessions and/or compulsions. It often results in decreased quality of life, poor social skills, and low occupational function.

\section{Objectives:}

This study aims to estimate the 12-month prevalence of OCD across 17 major European countries.

\section{Methods:}

A systematic review of the published literature reporting prevalence estimates of OCD was performed using the PubMed interface for Medline. To calculate the number of diagnosed prevalent cases OCD in each country, we multiplied age-and gender-specific diagnosed prevalence estimates by the United Nations population estimates for each forecast year ${ }^{1}$.

In those countries where no reliable prevalence estimates were found, estimates from comparable countries (or groups of countries when pooling of study results was performed) were used instead.

We limit our analysis to people aged 20 or older because of the inability of young children to articulate the aims of these behaviors and mental acts.

We estimate OCD prevalence for the period 2019-2029 in Austria, Belgium, Czech Republic, Denmark, Finland, France, Germany, Greece, Italy, Netherlands, Norway, Poland, Portugal, Spain, Sweden, Switzerland, and the United Kingdom. For this study, we define 12-month prevalent case of OCD as per the Diagnostic and Statistical Manual of Mental Disorders, Fourth Edition (DSM-IV) criteria.

\section{Results:}

There are an estimated 6.4 million cases of OCD in 2019. The 12-month prevalence in these countries ranges from 17 per 1,000 in Italy to 18 per 1,000 in Poland (Fig.1). The highest burden of OCD is among the population aged 20 to 40 , and the prevalence tapers off in the older age-groups. We forecast the case burden in 2029 will reduce to 6.2 million. The forecast 12-month prevalence in 2029 ranges from 16 per 1,000 in Italy to 17 per 1,000 in Norway. Over the next ten years, population aging will be the major factor driving the reduction in the prevalent cases of OCD (Fig.2).

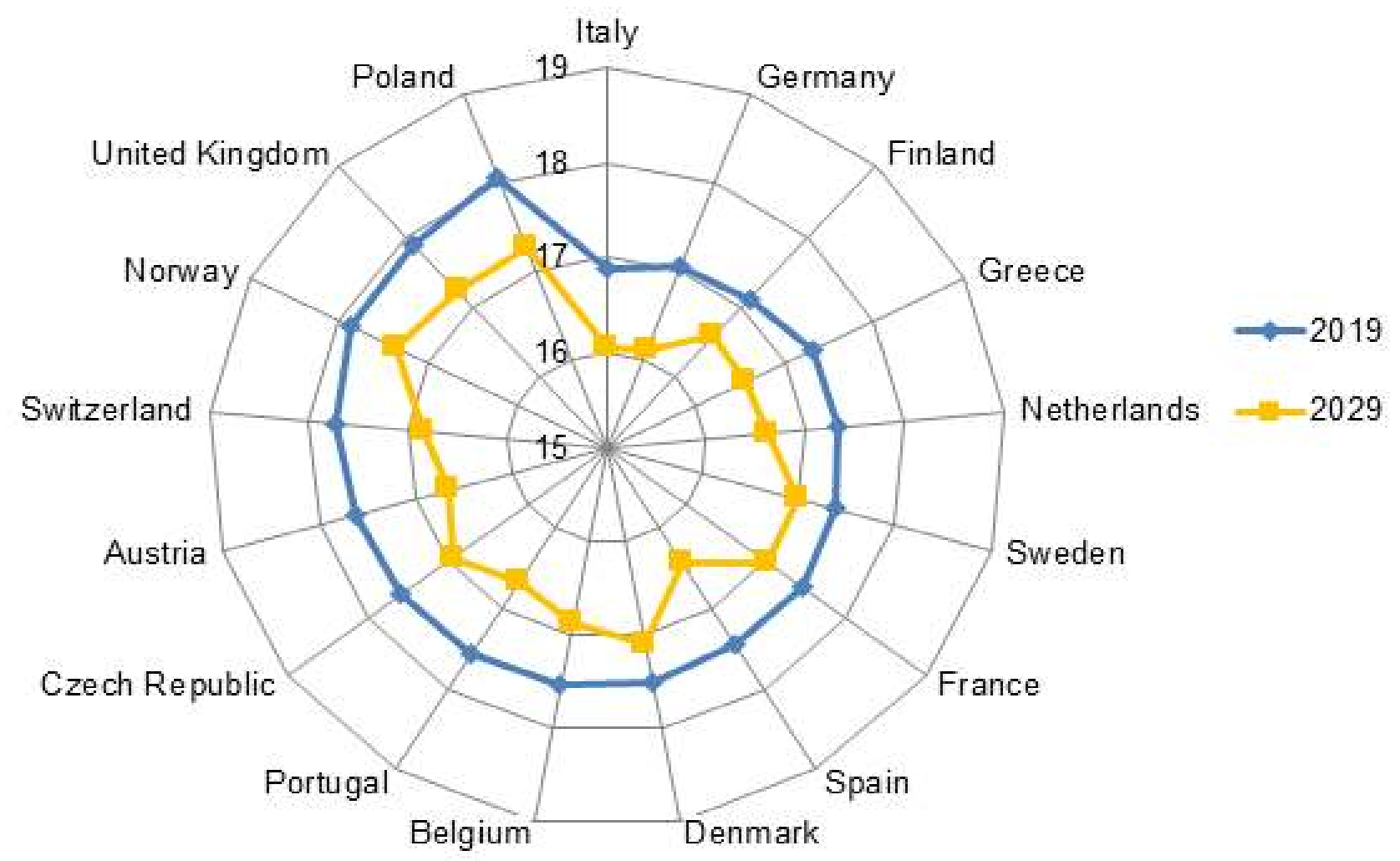

Figure 1. Prevalence of OCD per 1,000 among people aged 20+ in 2019 and 2029

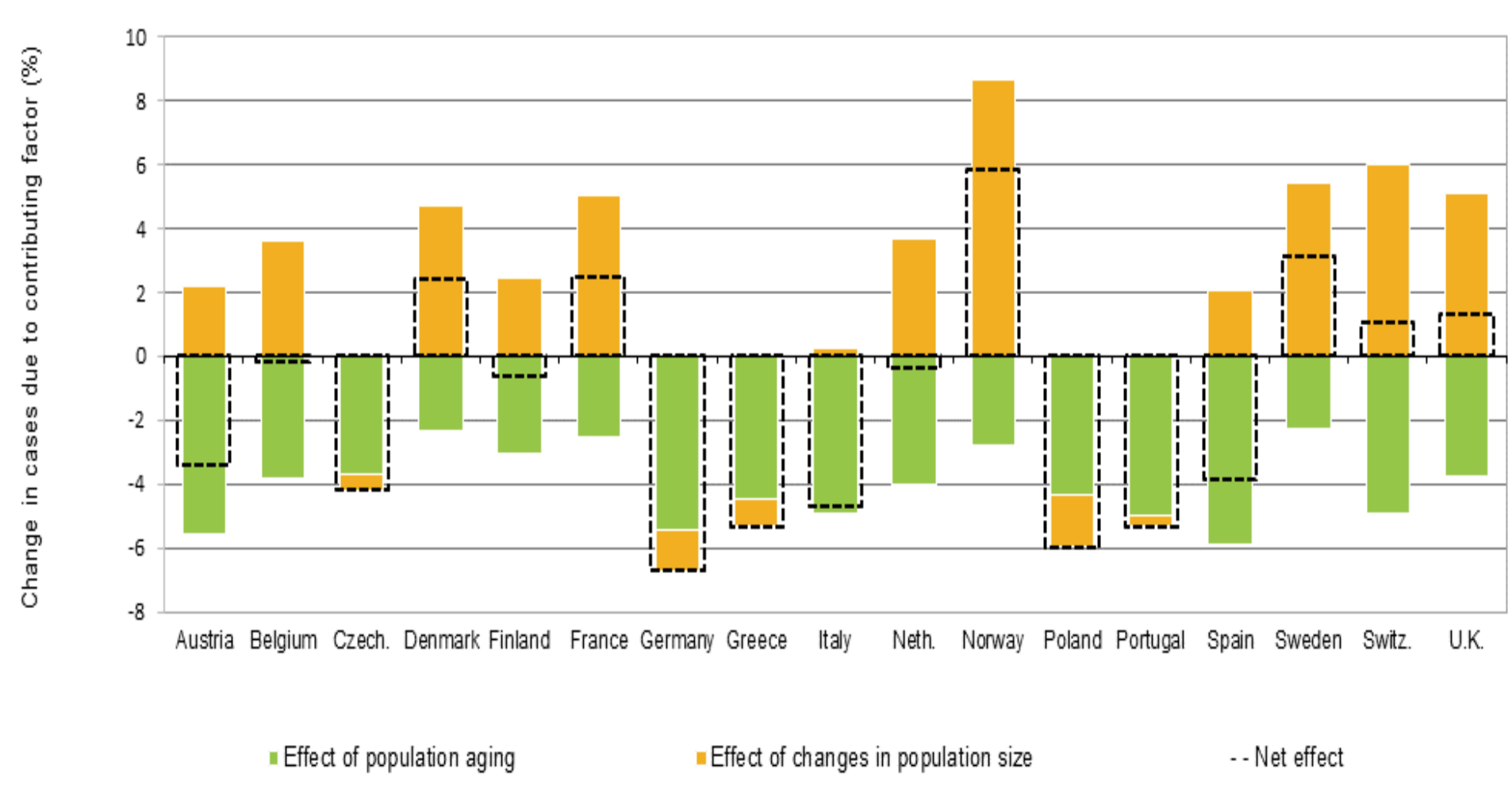

Figure 2. Relative sizes of the factors contributing to the trend in prevalent cases of OCD over the next ten years

\section{Conclusion:}

Over 6 million people are suffering with $O C D$ in the 17 major European countries, and this number will decrease marginally over the coming decade, given the combined effects of population aging and the changes in the population size.

\section{References:}

1. United Nations. Department of Economic and Social Affairs. Population Division. World Population Prospects: The 2015 Revision. Released 29 July 2015.

2. DRG. Decision Resources Group. Epidemiology. Obsessive Compulsive Disorder, 2019. 